\title{
Out of Pocket Payment by Inpatients After Health Sector Evolution Plan and Its Effecting Factors: A Report of Iran
}

\author{
Hesam Seyedin ${ }^{1}$, Mahnaz Afshari ${ }^{2,}{ }^{,}$, Parvaneh Isfahani ${ }^{3}$, Kobra Sharifkazemi ${ }^{2}$, Malihe Morshedi ${ }^{2}$ and \\ Amin Akbari ${ }^{2}$ \\ ${ }^{1}$ School of Health Management and Information Sciences, Iran University of Medical Sciences, Tehran, Iran \\ ${ }^{2}$ Department of Health Services Management, School of Health Management and Information Sciences, Iran University of Medical Sciences, Tehran, Iran \\ ${ }^{3}$ Department of Health Services Management, School of Public Health, Zabol University of Medical Sciences, Zabol, Iran \\ "Corresponding author: Department of Health Services Management, School of Health Management and Information Sciences, Iran University of Medical Sciences, Tehran, \\ Iran. Email: afshari.m@tak.iums.ac.ir
}

Received 2019 August 27; Revised 2020 February 16; Accepted 2020 February 21

\section{Abstract}

Background: The health transformation plan (HTP) was implemented in April 2014 in university hospitals to provide equitable access to healthcare, improve the quality of care, and protect patients against high costs of hospitals.

Objectives: The present study aimed to investigate out of pocket (OOP) payment by inpatients after the health sector evolution plan (HSEP) and its effective factors in hospitals affiliated with Iran University of Medical Science.

Methods: In this study, descriptive and cross-sectional research design was utilized. 277 patients at 5 hospitals affiliated with Iran University of Medical Sciences were selected via simple random approach. Checklists and hospital bills were used to collect data. Then the data were analyzed by SPSS 19.0 .

Results: The results indicated that OOP was $18.71 \%$ of the total hospitals expenditure. There was a significant relationship among insurance status, location, and $\mathrm{OOP}(\mathrm{P}<0.05)$.

Conclusions: The OOP rate of hospitalized patients was not in accordance with the goal set in the HSEP. Thus, policymakers and managers should take serious measures to decrease out-of-pocket payments.

Keywords: Health Expenditures, Inpatients, Out-of-Pocket, Hospital

\section{Background}

The health system consists of all organizations, people, and actions in order to promote, restore, or maintain health. It plays a significant role in improving the quality of life. The main objective of the health system is to promote health and respond to the people's needs and the society. The health system has four key functions, including the provision of health care services, resource generation, stewardship, and financing (1).

Conventional methods of health financing include taxes, social security, private insurance, donations, and out-of-pocket payments (OOPs). In the case of taxes, the government is responsible for health financing, and public revenues are the main source of health care funds. In social security, healthcare costs are covered through mandatory contributions by individuals. This method is based on wage-based premium payments by workers, employees, employers, private firms, and public organizations to social security funds. In private insurance, individuals can voluntarily seek coverage by various private health insurance companies and pay premiums proportionate to risk (2).

In some cases, donations from other countries and domestic or foreign institutions, which are offered for a variety of reasons, can serve as a source of finance along with other financing methods. When the government is unable to finance health care, the financial burden is directly imposed on people, forcing them to pay from their own pockets (2). OOP payment is one of the simplest and least effective payment methods (3) and the major source of health care funds in most developing countries (4). It is defined as direct payments made by individuals to health care providers at the time of service use. Despite its numerous drawbacks, OOPs account for a big portion of payments in the health system (3).

OOPs include formal or direct payments recorded in the hospital bills, informal payments that are not 
recorded, and payments for goods purchased by the patient (5). OOP increase can lead to catastrophic health expenditure (CHE). According to WHO, CHE occurs when a household's total OOPs equal or exceed $40 \%$ of its capacity to pay (6). Financial insecurity, as a result of CHE drives vulnerable groups into poverty in more than $90 \%$ of lowincome countries (7). It has been estimated that each year, 44 million households worldwide face CHE (8).

The fourth and fifth development plans emphasize the issue of equity in health care by setting objectives to increase the fair financial participation index (FFCI) by $90 \%$, decreasing people's share of health care costs to less than $10 \%$, and reducing the share of vulnerable households from CHE to 1\% (9). The HTP was implemented in April 2014 to provide equitable access to healthcare reduce OOPs, and improve the quality of care. This plan includes seven objectives for the treatment sector: reducing OOPs by inpatients of university hospitals, offering financial protection to patients with incurable diseases as well as disadvantaged patients, improving the quality of inpatient care in public hospitals, retaining physician in underdeveloped and disadvantaged regions, increasing the presence of resident specialists in public hospitals, improving the quality of outpatient care in public hospitals, and promoting natural childbirth/reducing C-section rate. All university hospitals in the country must provide the inpatient care needed by the patients without referral to the private sector for care, medicine or supplies, and OOPs must not exceed $10 \%$ of their total treatment costs (10).

The target population is all Iranians who have primary health insurance and visit the hospitals covered by this plan, and the Iranian Health Insurance Organization must provide insurance according to the relevant guidelines. OOP in the inpatient sector has been predicted to decrease by 7.1\% following the implementation of HTP (11). Toosi et al. (12) showed that OOP was decreased by $8.86 \%$ after HTP at university hospitals. Emamgholi Poor et al. (13) stated that, despite the decrease in the share of households in health care and health insurance by $46 \%$, the real rate of OOP by households increased by $16 \%$. Khammarnia's study (14) of urban and rural households in Zahedan Province showed that after HTP, about $12.99 \%$ of households encountered CHE with rural households that have a larger share.

\section{Objectives}

This study aimed to determine OOP payment by inpatients after health sector evolution plan and its effecting factors in hospitals affiliated with Iran University of Medical Science (IUMS).

\section{Methods}

This descriptive-analytical, cross-sectional study was conducted in Iran University of Medical Sciences in 2016. It consisted of all the discharged inpatients of university hospitals in Tehran. The sample size was estimated at 385 using Cochran's sample size formula at the $95 \% \mathrm{CI}$ and based on the rate of OOP financing in recent years (15), which has been about $50 \%(\mathrm{P}=0.5)$.

The procedure sample selection was as follows. First, 4 hospitals affiliated with Iran University of Medical Sciences were randomly selected. Then, samples were selected based on proportional allocation and convenience of the hospitals. Data were collected via a researcher-made checklist and the hospital bills. The first part of this checklist, called socio-demographic data, was associated with the demographic characteristics of the respondents, such as age, sex, and marital status. The second part was the detailed information about the cost of each therapeutic procedure, including 46 items (hoteling, physician's visit, and drug costs, laboratory exams, radiologic imaging, ultrasound, biophysical profile, delivery, operating room, surgeon's fee, assistant surgeon's fee, anesthesiologist's fee, and materials).

The data were analyzed via SPSS version 19 (SPSS Inc, Chicago, Il, USA) with descriptive statistics (e.g., frequency, percentage, mean, and standard deviation) and multiple regressions to examine the effect of demographic variables (e.g. sex, place of residence, insurance status, and hospitalization season) on OOP spending. The level of significant was considered $\mathrm{P}<0.05$.

\section{Results}

Due to the incomplete data and the reluctance of some patients, 277 out of 385 forms were completed. Table 1 shows the demographic characteristics of the patients, according to which $55.6 \%$ of patients were male, $52.7 \%$ were married, $46.7 \%$ had social security insurance and $91 \%$ were urban residents, and 76.1\% had elective admission.

The mean age of the patients was $35.32 \pm 24.97$ years old. $72.6 \%$ of the patients had no supplementary insurance. The average length of hospitalization was $5.75 \pm 6.58$ days. 9.7\% of patients (27 patients) lost their jobs due to illness. 31.4\% of patients entered in the waiting list due to the lack of financial affordability. The results showed that the highest percentage of payments in all the hospitals was made in the winter.

The results showed that mean of OOP from the total cost of the hospital in 5 hospitals was $18.71 \%$. Table 2 shows 


\begin{tabular}{|c|c|}
\hline Variable & Values \\
\hline \multicolumn{2}{|l|}{ Age } \\
\hline$<25$ & $101(36.5)$ \\
\hline $26-35$ & $48(17.3)$ \\
\hline $36-45$ & $24(8.7)$ \\
\hline $46-55$ & $28(10.1)$ \\
\hline $56-65$ & $39(14.1)$ \\
\hline Older 66 & $37(13.3)$ \\
\hline \multicolumn{2}{|l|}{ Health insurance type } \\
\hline Social Security Insurance Organization & $129(46.7)$ \\
\hline Medical Services Insurance Organization & $94(33.9)$ \\
\hline Imam Khomeini Health Insurance Organization & $2(0.7)$ \\
\hline No Insurance & $6(2.1)$ \\
\hline Other Insurance Organization & $46(16.6)$ \\
\hline \multicolumn{2}{|l|}{ Gender } \\
\hline Female & $123(44.4)$ \\
\hline Male & $154(55.6)$ \\
\hline \multicolumn{2}{|l|}{ Level of education } \\
\hline Illiterate & $85(32.3)$ \\
\hline Diploma & $134(51)$ \\
\hline Bachelor & $38(14.4)$ \\
\hline Master's degree & $4(1.5)$ \\
\hline $\mathrm{PhD}$ & $2(0.8)$ \\
\hline \multicolumn{2}{|l|}{ Type of admission } \\
\hline Elective & $211(76.1)$ \\
\hline Urgent & $58(21)$ \\
\hline Transfer from other centers & $8(2.9)$ \\
\hline \multicolumn{2}{|l|}{ Having a chronic disease } \\
\hline Yes & $61(22)$ \\
\hline No & $216(78)$ \\
\hline \multicolumn{2}{|l|}{ Location } \\
\hline Urban & $252(91)$ \\
\hline Rural & $25(9)$ \\
\hline \multicolumn{2}{|l|}{ Marital status } \\
\hline Single & $122(44)$ \\
\hline Married & $146(52.7)$ \\
\hline Others & $9(3.3)$ \\
\hline
\end{tabular}

the total cost and percentage of OOP from the total cost of the hospital.

According to regression analysis results (Table 3), the variables of insurance status and location were effective on the OOP payment rate in hospitalized patients $(\mathrm{P}<0.05)$. The rate of uninsured patients was higher than that of insured patients.

\section{Discussion}

In this study, the amount of OOP spending in university hospitals after HTP was examined. The results showed that OOP in 4 hospitals was $18.7 \%$ of the total hospital expenditure. The OOP rate of hospitalized patients was not under the health system transformation plan goal. However, the results of some studies in Iran indicated that OOP spending decreased following the implementation of HTP (16-21), which was consistent with our findings.

For example, a study via World Bank data showed that between 1995 and 2014, OOP spending decreased from $53.59 \%$ to $47.8 \%$ of total health spending. However, OOP spending in Iran was still higher than the global average (19). Also, another study showed that the share of OOP spending from total health spending decreased from $13.9 \%$ in 2013 to $5.5 \%$ in 2014. However, the rial amount of these payments did not decrease significantly (18). In 2017, studies showed that the health care costs of households significantly increased from 11,857,892 rials in 2012 to 16,021,227 rials in 2014 and 19,031,440 rials in 2014. In higher-income deciles, health care costs account for a higher share of total household expenditures, while health expenditures account for 6.3 percent of total expenditures in the tenth decile. This amount in the first decile is less than 4.8 percent. Health spending in 2014 grows at a lower rate than in 2013, which is less pronounced in 2015 and 2016 compared to 2014 (22).

Another study on a university hospital in 2016 showed that the cost of aortic valve replacement increased from 45,695,137.06 rials to $156,536,031.8$ rials after HTP. The share of OOP spending from the total cost decreased by $17.67 \%$ to 7.64\% after HTP. By adding a share of the plan to the hospital bill, the percentage of direct payments from patients will be significantly reduced. OOP costs were reduced by $9 \%$ for patients with health insurance and $11 \%$ for patients with social security insurance (23). Proper policy and monitoring of HTP implementation can have a significant impact on achieving the goals of the health system.

There was a significant relationship between OOP spending and the patient's place of residence. Wagstaff and Lindelow (24) showed that OOP was higher in rural areas than the urban areas of China. They attributed this finding to the lack of education, informational disadvantage, and the low-level facilities in rural areas. In Iran, rural residents have universal health coverage, receiving free services from various rural health centers, which reduces the treatment costs of the patients (24).

On the other hand, many rural residents do not have supplementary insurance. In this study, 8.3\% of the rural visitors of the hospital had no supplementary insurance. Sparrow et al. (25) studied health insurance access and OOP in Indonesia and showed that the Askeskin program improved access to healthcare and OOP in rural areas, but 


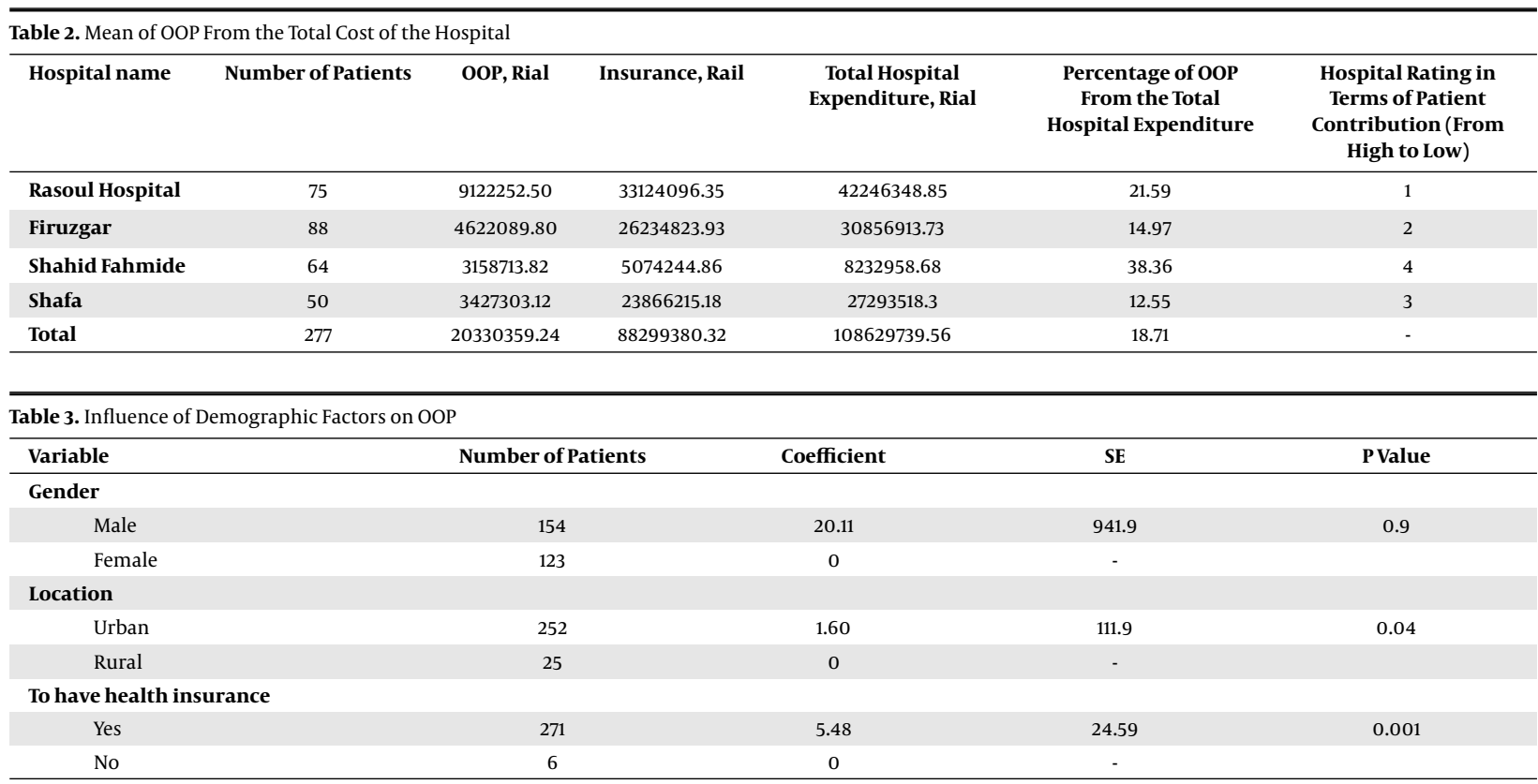

OOP spending increased in urban areas (25). Nonetheless, the health system can expand universal health coverage in rural and urban areas so that everyone can benefit from similar services.

There was a significant relationship between OOP and insurance status. Another factor affecting OOP spending is the insurance status of the patients. Insurance guarantees people's access to health care by ensuring that reimbursement by the insurer reduces OOP and the household's exposure to catastrophic health expenditures. People who are not covered by insurance have to pay directly for OOP medical expenses, medications, tests, and direct hospital costs. Therefore, they are more likely to face catastrophic medical expenses.

According to the results, about one-third of the patients felt pressure from treatment costs. Lack of attention to healthcare costs and increased probability of CHE can increase poverty. Health officials and managers need to implement programs across the country to reduce OOP for inpatient and outpatient services and services provided by the private sector. However, healthcare services can be very costly, especially for people in rural areas. Lack of effective protective mechanisms can make this group vulnerable to CHE. Therefore, healthcare authorities and policymakers must reduce the financial burden on the patients by focusing on prepayments and reducing the need for OOP. Although only the public hospitals were studied in this survey, it is suggested that more studies be conducted in other hospitals so that proper picture of OOP can be achieved.

\subsection{Conclusions}

The rate of OOP for inpatient services was 18.7\%. OOP spending by the inpatients of the studied hospitals was not in line with the goals set by the Ministry of Health. Therefore, a sustained decrease in OOP spending requires the development and implementation of large-scale plans at the national level for outpatient care.

\section{Acknowledgments}

All experts who participated in this research are highly appreciated.

\section{Footnotes}

Authors' Contribution: MA and HS designed research. MA and HS conducted research. AA, KS, and MM collected data, MA and PI wrote the paper. MA had primary responsibility for final content. All authors read and approved the final manuscript.

Conflict of Interests: No conflict of interest declared.

Ethical Approval: This research study was approved by the Ethics Committee at IUMS. Also, the confidentiality of the patients' names was observed through all stages of the research.

Funding/Support: Iran University of Medical Sciences funded this research. 


\section{References}

1. WHO. The world health report 2000: health systems: Improving performance. Geneva: World Health Organization; 2000.

2. Kolasa K, Kowalczyk M. Does cost sharing do more harm or more good? - a systematic literature review. BMC Public Health. 2016;16:992. doi: 10.1186/s12889-016-3624-6. [PubMed: 27633253]. [PubMed Central: PMC5025558].

3. Keshavarz A, Kalhor R, Javadi A, Asefzadeh S. Estimating out of pocket payments (oop) for medical cares in Qazvin Province in 2009. Hospital. 2012;10(39):71-7.

4. Hooda SK. Out-of-pocket payments for healthcare in India. $J$ Health Manage. 2017;19(1):1-15. doi:10.1177/0972063416682535.

5. Zarei E, Pouragha B, Khodakarim S. Out of pocket payment by inpatients of public hospitals after health sector evolution plan a crosssectional study in Tehran City. J Hospital. 2017;16(3):9-17.

6. Ekman B. Catastrophic health payments and health insurance: some counterintuitive evidence from one low-income country. Health Policy. 2007;83(2-3):304-13. doi: 10.1016/j.healthpol.2007.02.004 [PubMed: 17379351].

7. Shrime MG, Dare AJ, Alkire BC, O'Neill K, Meara JG. Catastrophic expenditure to pay for surgery worldwide: A modelling study. Lancet Glob Health. 2015;3 Suppl 2:S38-44. doi: 10.1016/S2214-109X(15)700859. [PubMed: 25926319]. [PubMed Central: PMC4428601].

8. Xu K, Evans D, Carrin G, Aguilar-Rivera AM. Designing health financing systems to reduce catastrophic health expenditure. Geneva: WHO; 2005.

9. Vosoogh Moghaddam A, Damari B, Alikhani S, Salarianzedeh MH, Rostamigooran N, Delavari A, et al. Health in the 5th 5-years development plan of Iran: Main challenges, general policies and strategies. Iran J Public Health. 2013;42(Supple1):42.

10. Akbari Sari A, Mosadegh Rad AM, Janbabaee Mola G, Mousavi SE. Cancer patient satisfaction following implementation of health transformation plan in a hospital: A brief report. J Mazandaran Univ Med Sci. 2018;28(162):149-54.

11. Zareie G, Mohammadi E. Investigating the Effect of Health Care Improvement Plan on the Payment of the Insured in Iranian Health Insurance Organization (Case Study: Hospitalized Patients in Collegiate Hospitals of Ilam City in December 2013 and 2014). Jlam Univ Med Sci. 2017;24(6):178-88. doi:10.18869/acadpub.sjimu.24.6.178.

12. Toosi Z, Soori E, Zamanian L, Falahati nia GH. Implementation of health system transformation plan in two axes: Promotion of normal vaginal delivery and reduction of out of pocket in hospitals affiliated to Hamadan University of Medical Sciences. Hakim. 2018;21(3):173-9.

13. Emamgholi Poor S. Justice in the distribution of the financial burden of health care costs in Iran. J Islam Bank Finance. 2018;24:131-47.
14. Khammarnia M, Peyvand M, Setoodezadeh F, Barfar E, kord Tamini A, Arefi UB, et al. Health expenditures by households after implementation of health transformational plan: A cross-sectional study. Payesh (Health Monitor). 2018;17(3):227-37.

15. World Health Organization. Health system financing profile by country. 2015, [cited 2015 Jul 23]. Available from: http://apps.who.int/nha/ database/Country_Profile/Index/.

16. Hessam S, Babaie J, Rostami T. The comparison of direct costs paid by inpatients before and after implementing health system transformation plan in Hashtrood and Mianeh Hospitals. Depict Health. 2019;8(3):161-8.

17. Mehrolhassani MH, Najafi B, Yazdi Feyzabadi V, Haghdoost AA, Abolhallaje $M$, Ansari $M$, et al. Total health expenditures and proportion of out-of-pocket payments in Iranian provinces; 2008-2014. Iran J Epidemiol. 2017;12(5Special Issue):1-12.

18. Karami M. Impact of health system reform on patients' formal payment in heart department: Case study. J Health Adm. 2018;21(72):90-8.

19. Behzadifar M, Beyranvand T, Jafari M, Behzadifar M, Taheri Mirghaed M, Martini M, et al. A description of the temporal pattern of outof-pocket expenditure related to Iranian Healthcare Services during 1995-2014. Iran J Public Health. 2018;47(10):1552.

20. Zahed Pasha Y, Mouodi S, Ahmadpour Kacho M, Hajitabar Z, Jahangir T, Bijani A. Comparing the hospital costs of the neonates admitted to NICU of Amirkola Children's Hospital Before and After the Implementation of the Health Sector Reform in Iran. Iran If Neonatol IJN. 2017;8(3):25-30.

21. Maharlou H, Barati O, Maher M. The study of inpatient services costs provided to cardiovascular patients referred to Al-Zahra Heart Hospital in Shiraz During 2nd half of 2013 and compare to the same time after Iranian Health Transformation Plan Implementation.J Healthcare Manage. 2016;7(20):31-8.

22. Fazaeli AA. Financial contribution of Iranian Urban Households in the Health System (2004-2016): With an emphasis on the health transformation plan. J Educ Commun Health. 2017;4(1):43-50. doi: 10.21859/jech.4.1.43.

23. Kavosi Z, Ghodrati J, Yusefi A. Comparison of paying out of pocket for aortic valve replacement (AVR) surgery before and after the implementation of healthcare reform in Shiraz Namazi Hospital in 2016. J Rafsanjan Univ Med Sci. 2018;17(7):657-68.

24. Wagstaff A, Lindelow M. Can insurance increase financial risk? The curious case of health insurance in China.J Health Econ. 2008;27(4):9901005. doi: 10.1016/j.jhealeco.2008.02.002. [PubMed: 18342963].

25. Sparrow R, Suryahadi A, Widyanti W. Social health insurance for the poor: Targeting and impact of Indonesia's Askeskin programme. Soc Sci Med. 2013;96:264-71. doi: 10.1016/j.socscimed.2012.09.043. [PubMed: 23121857]. 